\title{
CASASSA: A RELEVÂNCIA DE UM CENTRO DE ACOLHIMENTO PARA JOVENS LGBT MARGINALIZADOS NA CIDADE DE PRESIDENTE PRUDENTE-SP
}

Felipe Gasquez de Morais, Maria Gabriela Salvino Contre, Moisés Henrique dos Santos Leonel, Yeda Ruiz Maria,Victor Martins de Aguiar.

Universidade do Oeste Paulista - UNOESTE, Curso de Arquitetura e Urbanismo, Presidente Prudente, SP. E-mail: felipeg_morais@hotmail.com

\section{RESUMO}

O presente artigo visa compreender como as características físicas e sociais do espaço urbano colaboram para a existência de populações marginalizadas na cidade de Presidente Prudente - SP, ressaltando a vulnerabilidade social que a população de Lésbicas, Gays, Bissexuais, Travestis, Transexuais e Transgêneros - LGBT estão sujeitados. A partir deste panorama social busca-se analisar e ressaltar a importância de um espaço que atue como abrigo para essa população, como é o caso das Casas de Acolhimento LGBT, que estão surgindo gradativamente no Brasil. Tal importância e contribuição desses espaços de acolhimento será enfatizada com a análise do processo de implantação da CASASSA, primeiro projeto com esse caráter em Presidente Prudente-SP. A análise aqui apresentada da CASASSA ressalta sua história, características físicas e a forma como o local se organiza e se relaciona com o bairro em que está inserido.

Palavras-chave: LGBT; Casas de Acolhimento; CASASSA; CASA 1; Presidente Prudente

\section{CASASSA: THE RELEVANCE OF A SHELTER FOR MARGINALIZED YOUNG LGBT PEOPLE IN THE CITY OF PRESIDENTE PRUDENTE-SP}

\begin{abstract}
This article aims to understand how the physical and social characteristics of the urban space contributes to the existence of marginalized populations in the city of Presidente Prudente - SP, focusing in the social vulnerability that the LGBT population (Lesbian, Gay, Bisexual, Transgender) are subjected to. This social panorama seeks to analyze and emphasize the importance of a space that functions as a shelter for this population, as is the case of LGBT Reception Houses, which are gradually emerging in Brazil. The importance and contribution of these spaces will be emphasized with the analysis of the CASASSA implantation process, the first project of this character in Presidente Prudente - SP, accentuating the history, the physical characteristics and the way the place is organized and related to the neighborhood in which it is inserted.
\end{abstract}

Keywords: LGBT; Host Houses; CASASSA; CASA 1; Presidente Prudente.

\section{INTRODUÇÃO}

A situação atual do grupo de Lésbicas, Gays, Bissexuais, Travestis, Transexuais ou Transgêneros - LGBT, nas cidades, é resultado de um processo histórico com bastante resistência e que já não diz respeito mais somente à esfera privada, mas também a esfera pública e tem-se revelado cada vez mais em manifestação política pela busca da cidadania nos espaços urbanos (MOTA, 2017).

Apesar de limites e dificuldades na vivência urbana, para Cortés (2008, p. 160), os gays foram ocupando, por meio de lutas, diferentes lugares que lhes permitiram "socializar-se e construir um mapa paralelo e mais ou menos invisível de uma (oculta ou semioculta) 'cidade gay' com diferentes pontos de encontro (sexual ou não)".

Mesmo com o desenvolvimento de estratégias para fazer o uso dos espaços urbanos, a condição de vulnerabilidade social do grupo LGBT é uma questão certa e visível, levando em consideração o preconceito e a discriminação. 
Carvalho e Philippi (2014) esclarecem que existe uma lacuna no grau de escolaridade do público LGBT, o que somado com o preconceito social, pode se tornar um viés para o processo de marginalização. Marginalização, segundo Carvalho e Macedo Júnior (2017), principalmente na forma de prostituição e/ou tráfico de drogas, já que outras oportunidades não lhes serão oferecidas e nem o acesso aos serviços de saúde, educação e aparato jurídico-policial.

Com relação à esfera do trabalho, Garcia et al. (2010), observam que a orientação homossexual e a identidade trans acabam sendo elementos intensificadores das dificuldades para conseguir e/ou manter o emprego.

Por essas razões, nos últimos anos algumas casas de acolhimento LGBT foram implantadas ou estão em processo de implantação no país, através de iniciativas particulares ou voluntárias, como meio de atribuir outra perspectiva para este grupo, mas sem criar um vínculo de dependência social, conforme é o objetivo do Centro de Acolhimento Social LGBT - CASASSA, localizado no bairro Vila Santa Tereza em Presidente Prudente-SP.

O presente artigo apresenta assim como objeto de estudo a CASASSA, projeto idealizado por um grupo independente em 2017 e que visa acolher temporariamente homossexuais, transexuais e travestis, que sofram qualquer tipo de violência e estejam em situação de risco.

\section{METODOLOGIA}

O trabalho se desenvolveu através de consultas em fontes de dados secundárias, como teses, dissertações, periódicos e sites da Internet com o intuito de aprofundar a questão da necessidade de casas de acolhimento LGBT. Para tanto também foram realizados levantamentos documental e fotográfico da CASASSA, para a compreensão da dinâmica do local, e visitas in loco a fim de observar os indivíduos e suas respectivas relações no espaço.

\section{DISCUSSÃO}

No Brasil, existem atualmente casas de acolhimento em operação com a finalidade de abrigar essa parcela da sociedade que se encontra marginalizada, contribuindo na minimização da violência e na segregação do grupo LGBT.

De acordo com o objetivo geral do artigo, que é ressaltar a importância e contribuição desses espaços de acolhimento para a comunidade LGBT e para a própria sociedade, a tabela síntese abaixo discorre sobre quatro projetos em andamento no Brasil buscando apontar semelhanças na forma de organização das iniciativas (Quadro 1). 
Quadro 1. Levantamento de espaços de acolhimento LGBT no Brasil.

\begin{tabular}{|c|c|c|}
\hline CASA & LOCALIZAÇÃO & OBJETIVOS DO PROJETO \\
\hline CASA 1 & São Paulo (SP) & $\begin{array}{l}\text { O espaço, além de república de acolhimento para quem } \\
\text { está em situação de risco, também é um centro de cultura } \\
\text { que fornece atividades e cursos para os abrigados, com a } \\
\text { pretensão de reinserção dos mesmos na sociedade }{ }^{1} \text {. Cada } \\
\text { pessoa acolhida pode permanecer por até três meses no } \\
\text { projeto, período que pode ser estendido conforme as } \\
\text { necessidades individuais. E para ser morador, é preciso ter } \\
\text { mais de } 18 \text { anos, ter sido expulso de casa por ser LGBT ou } \\
\text { estar em situação de violência psicológica }{ }^{2} \text {. }\end{array}$ \\
\hline CASA NEM & Rio de Janeiro (RJ) & $\begin{array}{l}\text { É um espaço onde transexuais, travestis e transgêneros } \\
\text { encontram acolhimento, por meio de oficinas, debates, } \\
\text { festas e shows. O espaço independente e horizontal busca } \\
\text { empoderar o público LGBT em situação de vulnerabilidade } \\
\text { social }{ }^{3} \text { e é gerido somente por ativistas trans voluntários. } \\
\text { Além de acolhimento, o local oferece cursos ao público } \\
\text { LGBT, como de alfabetização, fotografia, gastronomia e o } \\
\text { "PreparaNem", que envolve aulas preparatórias para o } \\
\text { ENEM (Exame Nacional do Ensino Médio) }\end{array}$ \\
\hline CASA TRANSVEST & Belo Horizonte (MG) & $\begin{array}{l}\text { O projeto começou como curso pré-vestibular em 2016, no } \\
\text { bairro de Santa Tereza e atualmente é uma casa de } \\
\text { acolhimento exclusivamente para transexuais } \\
\text { desabrigadas }{ }^{5} \text { Com ações educacionais e } \\
\text { profissionalizantes, a casa mineira sobrevive com doações } \\
\text { e a renda de eventos, mesmo assim, busca se expandir } \\
\text { para áreas periféricas da região metropolitana }{ }^{6} \text {. }\end{array}$ \\
\hline CASA LGBT+ & Manaus (AM) & $\begin{array}{l}\text { A iniciativa ainda em estruturação prevê que a casa de } \\
\text { acolhimento funcione durante um ano com recursos } \\
\text { arrecadados de doações voluntárias sendo depois } \\
\text { transferida para o poder público. Assim, difere nesse } \\
\text { aspecto das outras casas de acolhimento citadas que ainda } \\
\text { não são vistas como políticas públicas }{ }^{7} \text {. Além de acolher o } \\
\text { público LGBT, a ideia é que no abrigo manauense os } \\
\text { acolhidos sejam capacitados para o mercado de trabalho e } \\
\text { recebam assistência social, jurídica e psicológica. }\end{array}$ \\
\hline
\end{tabular}

Fonte: Autores, 2018.

\footnotetext{
${ }^{1}$ Disponível em: <https://www.cartacapital.com.br/sociedade/casa-1-por-que-lgbts-precisam-de-uma-republica-de-acolhimento>. Acesso em: 03 de agosto de 2018.

2 Disponível em: <http://agenciapatriciagalvao.org.br/lgbt_/noticias-Igbt/casa-1-por-que-lgbts-precisam-de-uma-republica-de-acolhimento/>. Acesso em: 03 de agosto de 2018

3 Disponível em: <http://www.hypeness.com.br/2016/08/casa-nem-e-um-exemplo-de-amor-acolhimento-e-apoio-a-transexuais-travestis-etransgeneros-no-rj/>. Acesso em: 04 de agosto de 2018.

${ }^{4}$ Idem 4

5 Disponível em: <https://catracalivre.com.br/bh/educacao-3/gratis/projeto-cria-curso-pre-vestibular-gratuito-para-comunidade-trans-de-bh/>. Acesso em: 04 de agosto de 2018

${ }^{6}$ Disponível em: <http://agenciabrasil.ebc.com.br/geral/noticia/2017-06/abrigos-lgbt-se-espalham-e-reunem-historias-de-orgulho-e-superacao>. Acesso em: 04 de agosto de 2018.

Disponível em: <http://agenciabrasil.ebc.com.br/direitos-humanos/noticia/2017-08/campanha-arrecada-recursos-para-criar-casa-deacolhimento-lgbt-em>. Acesso em: 04 de agosto de 2018.
} 
É possível concluir, em vista desses quatro casos apresentados, que os projetos possuem pontos comuns na organização, principalmente quanto às formas de manutenção (doações, campanhas online, parcerias com empresas), já que atuam sem o apoio do poder público. Além de que, casas de acolhimento localizadas nas metrópoles do país, como a Casa 1, em São Paulo, e a Casa Nem, no Rio de Janeiro, hoje são sinônimos de um modelo, no que se refere à programação, período de estadia, gestão e estão influenciando a organização de outras iniciativas independentes como a CASASSA em Presidente Prudente.

\section{RESULTADOS}

A CASASSA está implantada no bairro Vila Santa Tereza, local tradicionalmente familiar e afastado do Centro de Presidente Prudente. A principal via de acesso ao bairro é a Av. Washington Luiz, a qual estabelece relação direta entre o bairro e o quadrilátero central da cidade (Figura 1).

Figura 1: Relação da CASASSA com o centro da cidade de Presidente Prudente.

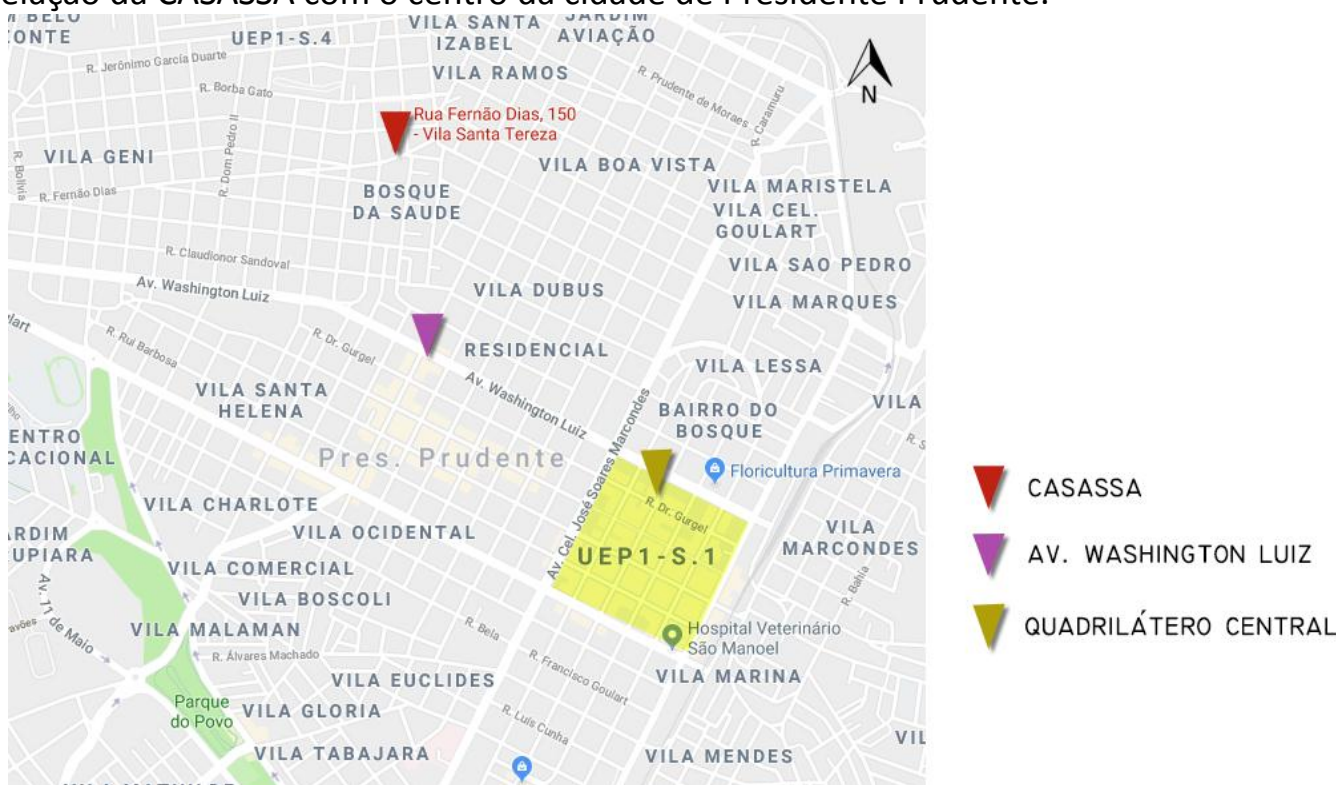

Fonte: Google Maps, 2018. Editado pelos autores, 2018.

A ideia da casa de acolhimento LGBT (Figura 2) foi liderada por um grupo independente, após uma discussão sobre machismo e homofobia durante a Semana da Diversidade de 2016, no Centro Cultural
Matarazzo de Presidente Prudente. A partir daí, chegaram à conclusão que existia a necessidade de um projeto semelhante ao da Casa 1, localizado em São Paulo, na cidade.

Figura 2: Varanda da CASASSA, localizada no bairro Vila Santa Tereza.

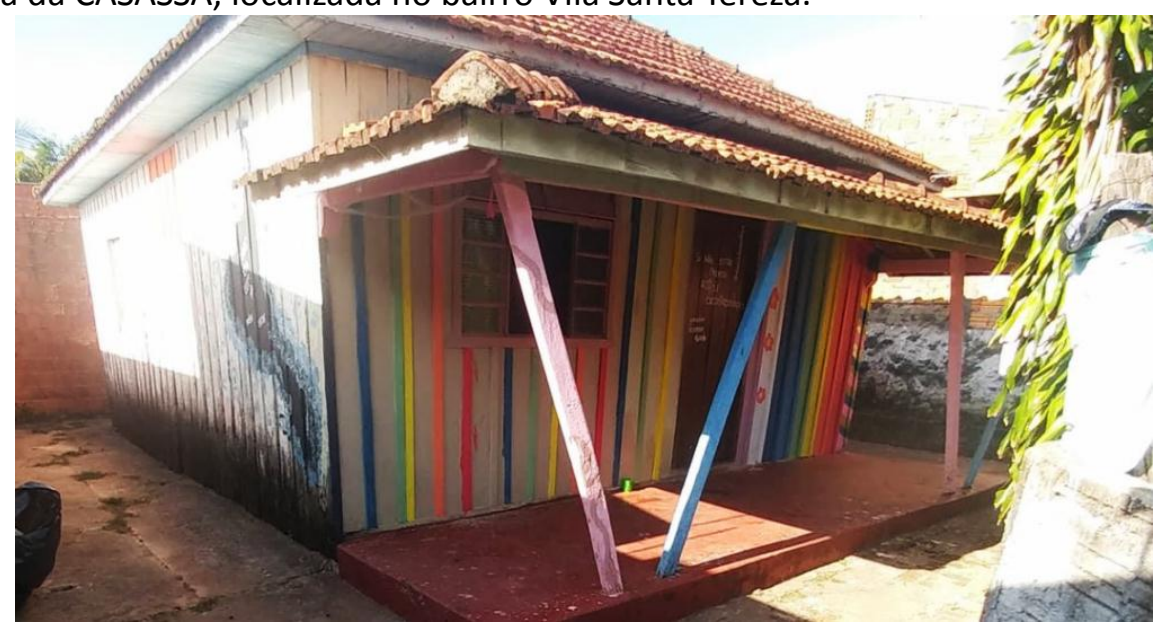

Fonte: Autores, 2017. 
No início de 2017, o grupo de maneira improvisada resolveu alugar uma casa localizada nos fundos do terreno em que está à casa de um dos coordenadores do projeto, dando então início as atividades da CASASSA. A casa alugada se caracteriza por sua estrutura de madeira e os seus ambientes estão dispostos em uma organização bastante simples: 1 Sala, 3 Quartos, 1 Copa e 1 Banheiro. Estes ambientes posteriormente foram readequados para atender a demanda dos jovens acolhidos e a maioria dos móveis e dos aparelhos eletrodomésticos do projeto foi arrecadado por meio de doações.

No presente artigo não serão aprofundadas questões arquitetônicas do espaço, mas sua organização, estrutura administrativa, atividades oferecidas em prol da coletividade e o retorno já obtido da CASASSA pela sociedade.

Com a intenção de melhorar a organização do projeto, foram criados em 2017 grupos de trabalhos: acolhimento emergencial, financeiro, doações, educação e cultura, atendimento, divulgação e jurídico. Por mais que exista essa divisão, no fim, os membros do projeto acabam se envolvendo em todos os grupos de trabalho.

Os membros a frente do projeto se caracterizam por compor um grupo de pessoas majoritariamente jovens militantes da causa, das mais diversas formações, o que auxilia na setorização das atividades. Em 2018, a equipe da CASASSA contava com 10 membros atuando regularmente e em torno de 25 apoiadores. A manutenção do espaço estava sendo realizada através de doações, bazares e rifas.

A etapa de acolhimento e estadia na CASASSA se dá semelhante ao da Casa 1, em São Paulo, onde a pessoa acolhida pode permanecer por até três meses no projeto, período estendido conforme necessidades individuais. $O$ projeto até junho de 2018 havia acolhido em torno de 6 pessoas. Essa demanda foi recebida, normalmente, através da rede social ou de amigos próximos dos membros e voluntários do projeto. Após recebê-los, a equipe do grupo de trabalho de acolhimento, composta por 3 psicólogos, realiza um processo de triagem com a pessoa que será acolhida, e na entrevista são levantados seus potenciais, fraquezas e destinações à cursos.

O Rotaract Clube de Presidente Prudente, grupo de jovens de 18 a 30 anos que realiza projetos comunitários pela cidade, promoveu em outubro de 2017 uma ação na
CASASSA. A ação realizou a pintura de um dos ambientes internos do espaço, sendo os materiais utilizados vindos de outra iniciativa do Clube no bairro Morada do Sol de Presidente Prudente. O grupo Levante Popular da Juventude também busca apoiar a CASASSA em diferentes ações, estando presente desde a concepção inicial do projeto. Além de contribuir nas discussões iniciais, o Levante em 2017 promoveu no espaço parte da "Semana Nós por Nós", evento realizado em diferentes cidades do Brasil, e ajudou na reforma e pintura da CASASSA.

A CASASSA também tem como um de seus objetivos minimizar estereótipos da comunidade LGBT e a partir da realização de eventos culturais no local, como a "Noite Musical" e o "Bazarzasso" vem buscando aproximar o projeto dos moradores do bairro e do público não LGBT, uma vez que um dos seus desafios tem sido a aceitação do espaço sem preconceitos.

Essas questões ainda estão em processo de discussão e de implantação na CASASSA. No entanto, são processos importantes de acompanhamento a fim de destacar as dificuldades colocadas quando se busca inserir e dar visibilidade ao público LGBT devido à ausência de políticas públicas, sobretudo, em uma cidade média como Presidente Prudente.

\section{CONCLUSÃO}

Tendo em vista o que fora analisado, é possível afirmar que o surgimento de casas de acolhimento LGBT em situação de vulnerabilidade social são um amparo, que tem como objetivo principal a reinserção destes na sociedade, uma vez que ainda nos dias de hoje o preconceito contra a comunidade LGBT é algo latente.

A partir da análise dos quatro projetos de casas de acolhimento LGBT em andamento no Brasil, percebe-se que estes possuem pontos em comum na sua organização, principalmente quanto às formas de manutenção (doações, campanhas online, parcerias com empresas) e que a participação do poder público nesses espaços é basicamente nula. Questão que não difere do objeto de estudo do trabalho, a CASASSA, tendo em vista que seu início ocorreu por meio de financiamento coletivo dos próprios organizadores do projeto, portanto, sem a participação do poder municipal, pois casas de acolhimento ainda não são vistas como políticas públicas. 
É válido ressaltar a importância que esta casa de acolhimento agrega a uma cidade de médio porte como Presidente Prudente, principalmente por se tratar de um projeto implantado em um bairro tradicionalmente familiar, o que vem dando maior visibilidade para as questões e desafios que cercam a comunidade LGBT. O projeto da CASASSA então se revela significativo para a luta LGBT na cidade, logo não apenas como equipamento de acolhimento provisório, mas também para a transformação de pessoas em vulnerabilidade social.

\section{REFERÊNCIAS}

CARVALHO, C. O.; MACEDO JÚNIOR, G. S. 'Isto é um lugar de respeito!': a construção heteronormativa da cidade-armário através da invisibilidade e violência no cotidiano urbano. Revista de Direito da Cidade, v. 9, n. 1, p. 103116, 2017. https://doi.org/10.12957/rdc.2017.26356

CARVALHO, L.; PHILIPPI, M. M. Percepção de lésbicas, gays e bissexuais em relação aos serviços de saúde. Universitas: Ciências da Saúde, v. 11, n. 2, p. 83-92, 2014.

CORTÉS, J. M. G. Políticas do espaço: arquitetura, gênero e controle social. São Paulo: Senac, 2008.

GARCIA, M. R. V. et al.“Vida loka”: estilo de vida e vulnerabilidade à violência e ao abuso de drogas entre jovens LGBT em situação de rua. In: ENCONTRO REGIONAL DA ASSOCIAÇÃO BRASILEIRA DE PSICOLOGIA SOCIAL, 10., 2010. São Paulo. Anais eletrônicos... São Paulo: ABRASPO, 2010. Disponível em: <http://www.usp.br/nepaidsabia/images/BIBLIOT ECA/PDF/apresentacoes/ $\mathrm{x}$ 20encontro\%20regio nal\%20da\%20abrapso.pdf>. Acesso em: 02 jun. 2018.

MOTA, M. P. Do espetáculo da diversidade sexual à performatividade do corpo identitário: olhares sobre a XX Parada do Orgulho LGBT de São Paulo. Revista Bagoas-Estudos gays: gêneros e sexualidades, v. 10, n. 15, p. 60-74, 2017.
Recebido para publicação em 09/08/2018

Revisado em 24/08/2018

Aceito em 03/09/2018 